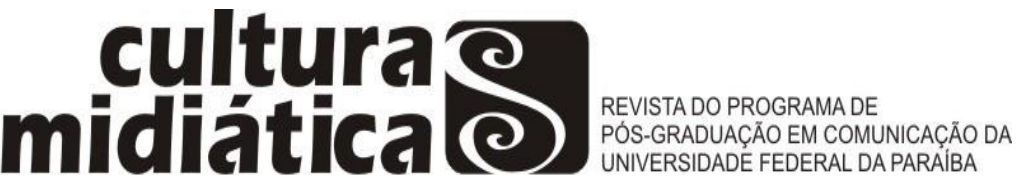

\section{Experiências estéticas provenientes das pequenas crises em Serguei Rock Show}

\author{
Aesthetic experiences in Gumbrecht: Serguei Rock Show
}

\author{
Tarcis PRADO JUNIOR ${ }^{1}$ \\ Moises CARDOSO ${ }^{2}$ \\ Franco IACOMINI JUNIOR ${ }^{3}$ \\ Aline Aparecida de Souza VAZ ${ }^{4}$
}

\begin{abstract}
Resumo
O presente artigo analisa o programa de TV por assinatura, Serguei Rock Show (2011), a partir de cenas que evocam o conceito das "pequenas crises" de Gumbrecht (2006). Por meio da decupagem e decodificação das imagens, metodologia proveniente da análise fílmica, revisitada, aqui, para a análise audiovisual, a seleção das cenas analisadas, de cinco episódios diversos, advém do semi-simbolismo: no plano da expressão e do conteúdo. As cenas selecionadas para o devido estudo são concernentes aos momentos em que o protagonista aborda "Dicas de Sexo", atuando, por vezes, como pseudoautoridade no assunto. Os resultados mostram que a experiência estética de Gumbrecht pode ter lugar em programas de TV, como pequenas crises expostas ao nosso cotidiano.
\end{abstract}

Palavras-chave: Experiência estética. Análise audiovisual. Semi-simbolismo. Pequenas crises. Serguei Rock Show.

\begin{abstract}
This article analyzes the pay-TV program, Serguei Rock Show (2011), from scenes that evoke the concept of the "small crises" of Gumbrecht (2006). By means of the decupagem and decoding of the images, methodology from the filmic analysis, revisited here for the audiovisual analysis, the selection of the analyzed scenes, of five different episodes, comes from the semi-symbolism: in the plane of expression and content. The scenes selected for the due study are related to the moments in which the protagonist

\footnotetext{
${ }^{1}$ Doutorando no Programa de Pós-Graduação em Comunicação e Linguagens da Universidade Tuiuti do Paraná (UTP). Professor nos cursos de Comunicação e marketing (UTP). Membro do Grupo de Pesquisa JOR XXI da UTP. E-mail: tarcisjr@yahoo.com.br

${ }^{2}$ Doutorando no Programa de Pós-Graduação em Comunicação e Linguagens (UTP). Professor do Curso de Publicidade e Propaganda (FURB e FAMEG). Membro do Grupo de Pesquisa JOR XXI da UTP.

E-mail: beiocardoso@gmail.com

3 Doutorando no Programa de Pós-Graduação em Comunicação e Linguagens (UTP). Jornalista e professor na Faculdade Fidelis. Membro do Grupo de Pesquisa JOR XXI da UTP.

E-mail: fiacomini@gmail.com

${ }^{4}$ Doutoranda pelo Programa de Pós-Graduação em Comunicação e Linguagens da Universidade Tuiuti do Paraná. Pesquisadora no Grupo de Pesquisa Desdobramentos Simbólicos do Espaço Urbano nas Narrativas Audiovisuais - GRUDES (UTP).E-mail: alinevaz88@ hotmail.com
} 


\section{midiäticale}

approaches "Sex Tips", sometimes acting as a pseudo-authority on the subject. The results show that the aesthetic experience of Gumbrecht can take place in TV programs, like small crises exposed to our daily life.

Keywords: Aesthetics. Gumbrecht. Serguei.

\section{Introdução}

Programas televisivos podem proporcionar ao (tele)espectador as condições para a apreensão estética, ganhando significações na relação entre os planos do conteúdo e da expressão, que para Jean-Marie Floch (2001, p. 29) referem-se aos sistemas semisimbólicos, definidos "pela conformidade não entre os elementos isolados dos dois planos, mas entre categorias da expressão e categorias do conteúdo". Desse modo, as relações semi-simbólicas podem sugerir os efeitos desejados em relação à mensagem, resultando na relação entre aquele que é olhado e olhante (DIDI-HUBERMAN, 1998), pois a recepção do (tele)espectador, no sentido clássico de alguém que vê TV ou simplesmente a assiste pela web, é o que define o próprio sentido da experiência, entendida, aqui, como estética. Assim, nota-se que "um novo estado universal do mundo, sempre será uma exceção que, de maneira totalmente natural e de acordo com cada situação individual, desperta em nós o desejo de detectar as condições (excepcionais) que a tornaram possível" (GUMBRECHT, 2006, p. 51).

Esta exceção - experiência estética revelada no elo tramado entre aquele que olha e é olhado - revela-se em situações, por vezes, prosaicas e que acontecem por interrupções no fluxo da vida cotidiana: "uma vez que ela se opõe ao fluxo pela nossa experiência cotidiana, os momentos da experiência estética se parecem com pequenas crises" (GUMBRECTH, 2006, p. 51). Assim, chamando ao texto conceitos de reflexões estéticas, caracterizamos a presente pesquisa como uma análise fílmica/audiovisual quanto aos elementos do conteúdo e da expressão, com uma pesquisa qualitativa exploratória de amostra não-probabilística por julgamento de frames do programa Serguei Rock Show, exibido em um canal de TV por assinatura, em 2011. Vale destacar que a investigação é desenvolvida sobre o arquivo disponível online do programa em uma plataforma digital, que funciona como a memória da emissora.

Manuela Penafria (2009) adverte a inexistência de uma metodologia universalmente aceita para a análise das imagens em movimento, porém observa um 


\section{midiätica@e}

caminho que deve ser percorrido, implicando em duas etapas importantes, as quais nos apropriamos para o devido estudo: decupar e compreender as imagens selecionadas do programa televisivo Serguei Rock Show, encontradas em cinco episódios diversos ${ }^{5}$, compreendendo a presença das "pequenas crises" (GUMBRECHT, 2006) na dinâmica do programa televisivo. Nele, o roqueiro Serguei aparece em diversos quadros, falando sobre música, cantando, entrevistando participantes convidados e também criticando moda e comportamento. Em todos os dez episódios, produzidos pelo canal Multishow, existe um quadro em que o cantor dá "Dicas de Sexo" e são esses recortes que serão apresentados como exemplos do que Gumbrecht (2006) entende como "experiências estéticas" no âmbito das pequenas crises.

\section{Sérgio Augusto Bustamante: Serguei}

Sérgio Augusto Bustamante, nascido em 1933, mais conhecido como Serguei, é carioca do bairro de Rio Comprido, zona norte do Rio de Janeiro. É filho único de um funcionário da $I B M$ e uma dona de casa. Teve forte influência de sua avó com quem foi morar nos Estados Unidos, em sua juventude. Sempre à frente de sua época, aos 17 anos já andava por Copacabana - em plenos anos 1950 - com camiseta preta, barriga de fora, calças saint-tropez, cintura baixa, botas de salto alto e cinto vermelho. Como ele mesmo reconhece: “Era um escândalo!”. (SCHILLER, 1997, p. 21).

Em seu depoimento para o livro de João Henrique Schiller (1997), o músico diz que sempre viveu uma vida sob risco, despretensiosa e pautada pela exacerbação da sexualidade: "Posso ser muito rock n'roll, muito underground, muito pele, mas tenho muito Hollywood em mim, muita purpurina, e sempre fui muito puto" (SCHILLER, 1997, p. 21).

$\mathrm{Na}$ carreira profissional, o roqueiro teve altos e baixos, muito por conta do seu jeito irreverente de ser. Num de seus empregos, no Banco Boavista, conta que foi demitido porque "ficava amarradão andando de elevador pra baixo e pra cima". Depois passou para o setor de aviação e trabalhou na Loyd Aéreo, Cruzeiro do Sul e Varig além da PanAir do Brasil. Nesta última tinha momentos de descontração e exibição de talento, em pleno voo:

\footnotetext{
${ }^{5}$ Os episódios estão hospedados dentro do site do Multishow que é exibido como uma websérie.
} Disponível em: <http://multishow.globo.com/webseries/serguei-rock-show/>. Acesso em: 05 set. 2016. 


\section{midiätica@e}

[...] eu era chefe de equipe, e naquela época eu tinha uma voz muito fina e imitava Dalva de Oliveira. Íamos para a cauda do avião, depois de servirmos à todos, para eu cantar as músicas da Dalva e também para imitar o Elvis Presley. Eu sempre cantava e gostava de ver o Elvis cantando e dançando (SCHILLER, 1997, p. 24).

Na Varig, devido ao seu estilo andrógeno, acabou sendo demitido. Segundo seus superiores, aquele comportamento não era compatível com a função de um comissário de bordo. Serguei diz que seu trabalho na aviação foi o que permitiu conhecer muitos lugares pelo mundo. Morou em Long Island nos Estados Unidos onde teve contato com diversos estilos musicais como o jazz, blues, boogie woogie, e o rhytm and blues, além de ter Ray Charles como sua referência. Nessa época, tinha uma banda, a The Centaurs, e participou de diversos festivais estudantis. (PINHEIRO, 2015).

A carreira de roqueiro começou em 1966 com a gravação do compacto, As alucinações de Sergei ${ }^{6}$ e Eu não volto mais. Seus trabalhos não obtiveram êxito comercial, mas o que chamava mesmo a atenção eram suas performances no palco. Seus trejeitos mimetizavam e traduziam também a contracultura e o rock, dois estilos comportamentais e musicais emergentes na época. $O$ artista fazia um grande contraponto aos expoentes da Jovem Guarda (PINHEIRO, 2015), sempre com seus comportados terninhos.

Eram tempos de ditadura no Brasil e censura a diversos tipos de manifestações, principalmente as que indicavam direções opostas ao que o país entendia como status quo. Em 1967 Serguei apareceu na revista Intervalo $^{7}$ ao protestar em cima de uma estátua no Rio de Janeiro, com o rosto maquiado defendendo a liberdade de imprensa, o direito de "ser jovem e feliz" e criticando a Guerra (Vietnã). Décadas mais tarde, numa entrevista à um programa de TV, relataria que neste episódio, quando os militares o prenderam acusando-o de comunista, ele teria mostrado uma tatuagem da bandeira dos Estados Unidos no seu braço e que isso teria determinado sua libertação.

Serguei, nesta época, não era aceito por nenhum dos lados, pois era muito transgressor para os militares e o padrão cultural vigente - enquanto de acordo com os

\footnotetext{
${ }^{6}$ Nesse trabalho o produtor musical sugere a mudança do nome, excluindo a letra " $u$ ", por isso o nome é Sergei.

${ }^{7}$ A revista Intervalo circulou nos anos 1960 e 1970 dedicava reportagens aos astros e estrelas da televisão brasileira. Disponível em: <http://wp.clicrbs.com.br/almanaquegaucho/2013/05/24/noticias-datelinha/?topo=13,1,1,,13>. Acesso em: 27 mai. 2016.
} 


\section{midiätica@e}

valores da esquerda era considerado alienado, já que a estética do rock estava sendo compreendida como um pacto com os valores imperialistas. Em um salto no tempo, no ano de 2011, o canal Multishow produz o programa protagonizado por Serguei, totalizando 10 episódios, que podem ser revistos na plataforma online da emissora.

\section{Serguei Rock Show - pequenas crises}

A experiência estética inerente a cotidianidade, apesar de apontar para um novo estado universal do mundo, sempre será uma exceção que, de maneira totalmente natural e de acordo com cada situação individual, despertará em nós o desejo de detectar as condições (excepcionais) que a tornaram possíveis (GUMBRECHT, 2006).

O “conteúdo da experiência estética" (Ibid., p. 54) seria concernente aos sentimentos íntimos, as impressões e as imagens produzidas pela nossa consciência enquanto inacessíveis aos nossos mundos historicamente específicos. Há a impressão de uma "finalidade sem fim", por exemplo, de um "ser desvelado" ou de um objeto e seu conceito e sua "aparência", uma vez que são desvinculados do seu contexto. Diferentemente desse conteúdo, os “objetos da experiência estética” seriam as coisas suscetíveis de desencadear tais sentimentos, impressões e imagens, o templo grego, no ensaio de Heidegger (1936), por exemplo, ornamentos de papel de parede e o mar para Kant (1889) e, de acordo com Seel (1991), qualquer objeto.

As "condições da experiência estética" são circunstâncias situacionais historicamente específicas nas quais a mesma estaria baseada. Desinteresse, por exemplo, é a distância diante de todos os propósitos práticos que nós viemos adotando como uma condição universal da experiência estética (mesmo se tudo indica que se tornou sua pressuposição na cultura ocidental somente desde o século XVIII). E, finalmente, podemos chamar de "leitos da experiência estética" as consequências e as transformações decorrentes, que permanecem válidas além do momento exato em que ocorrem.

A experiência estética nos revela como epifânicas, isto é, ela acessa o sensível repentinamente "como um relâmpago" (GUMBRECHT, 2006, p. 55) e desaparece de repente e irreversivelmente, sem permitir-nos permanecer com ela ou que possamos estender sua duração. As cenas selecionadas do programa de TV, sublimando-se o 


\section{midiätica@e}

aspecto nonsense, demonstram esta noção de epifania, o que veremos com maior precisão durante a análise.

Referente ao processo analítico, é de suma importância ressaltar que no decorrer do texto serão apresentadas palavras de baixo calão (elas quebram as normativas acadêmicas tradicionais, mas são importantes para caracterizar o objeto de pesquisa, na sua totalidade). Alguns diálogos foram suprimidos, em comum acordo entre os autores deste artigo, por contê-las em demasia expressões vulgares. Por sua vez, existem aquelas que optamos por manter, justificando-se pelo entendimento de sua força na expressão narrativa.

O programa Serguei Rock Show, estreou no ano de 2011 em um canal de assinatura de TV, pertencente às organizações Globo. Nos dez episódios do programa, Serguei protagonizava diversos quadros, desde conselhos da vida em geral, passando por análises críticas de bandas e histórias sobrenaturais, até as "Dicas de Sexo", quadro fixo nos episódios e objeto de nossa análise neste artigo. Na Figura 01 temos Serguei, no primeiro episódio, do lado direito do vídeo, de olhos fechados e um rapaz falando algo ao seu ouvido. O balão com a inscrição "Dicas de Sexo" denota que a pessoa está fazendo alguma pergunta ou "soprando" alguma informação sobre o assunto. Logo em seguida, surge o protagonista que apresenta sua dica: "Pra transar, pra transar, assim, quem tiver doente pode ir à farmácia e comprar Viagra, né? Ou similares. Quem não tiver doente, vai que nem eu, na cara de pau, do jeito que é, entendeu? Alguma coisa sobe, alguma coisa desce, o que desce sobe, normal, como outra pessoa qualquer". 


\section{midiática@ \\ REVISTA DO PROGRAMA DE \\ PÓS-GRADUAÇÃO EM COMUNICAÇÃO DA \\ UNIVERSIDADE FEDERAL DA PARAIBA}

Figura 01. Vinheta episódio 01 "Dicas de Sexo".

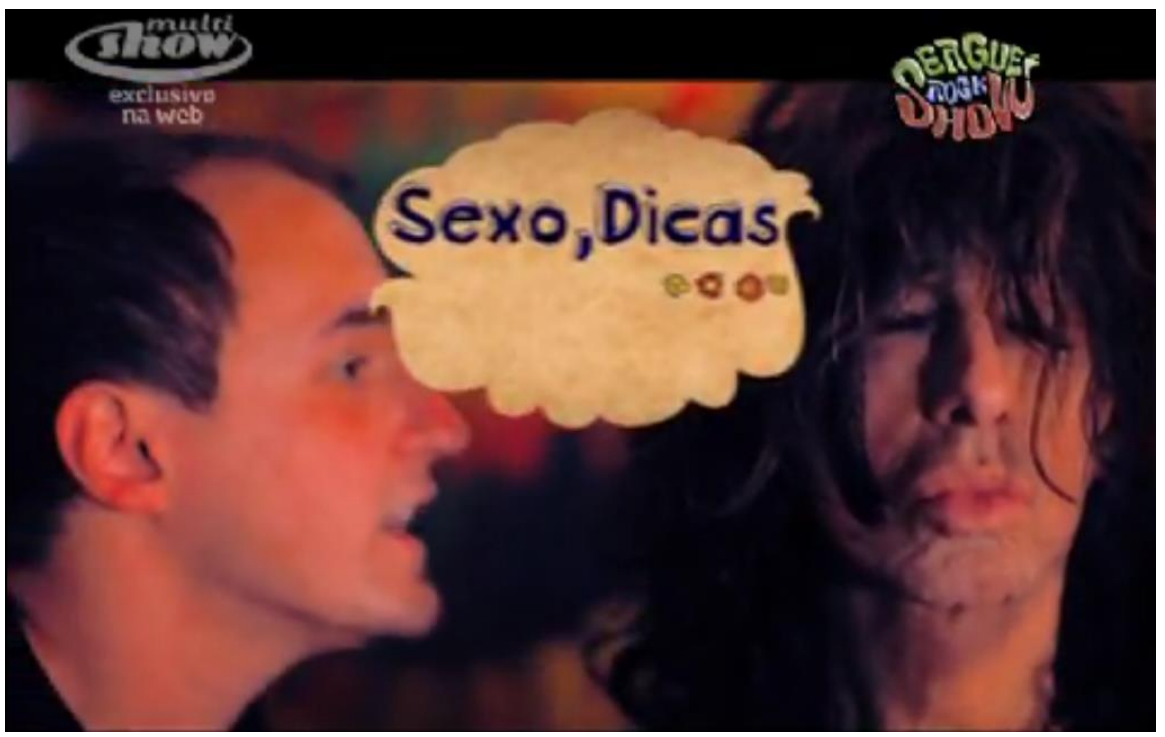

Fonte: Serguei Rock Show (2011).

O que se percebe nesta recomendação é, em primeiro lugar, a coerência de uma personalidade exótica com a enunciação à respeito de algo natural de um comportamento de base contracultural, ou seja, não é novidade vindo do próprio personagem. O que estabelece no entanto, a pequena crise (GUMBRECHT, 2006), é o caráter de quebra de ordinariedade nas cenas do programa. O que se poderia esperar em relação ao quadro "Dicas de Sexo" seria, talvez, algo que mostrasse a sexualidade nas mais diversas formas de expressão (desde kamasutra, por exemplo, até certos tipos de comportamento sexual). No entanto, a dica se mostra demasiado nonsense e essa característica é que revela a pequena crise da cena, pois, rompe com a expectativa que esperamos de um aconselhamento, mesmo vindo de alguém sob a pecha de hippie ou outro expoente beatnik.

No quadro seguinte (Figura 02) ele dá sequência às suas dicas: "Eu acho o seguinte, antes de transar, é muito legal ter uma ereção, sabia? Tem que ter uma ereção, antes de transar. É isso aí”. Ou seja, o que seria condição para o ato sexual (pelo menos os que envolvessem à figura masculina) convencional, Serguei faz questão de afrmar quase que o óbvio: tem que ter uma ereção. Claro que isso causa estanheza no (tele)espectador, o que Gumbrech (2006) aponta como o compartilhamento da condição de expecionalidade das experiências estéticas. 


\section{midiática@ \\ REVISTA DO PROGRAMADE \\ PÓS-GRADUAÇÃO EM COMUNICAÇÃO DA \\ UNIVERSIDADE FEDERAL DA PARAIBA}

Figura 02. Episódio 01 "Antes de transar, tenha uma ereção".

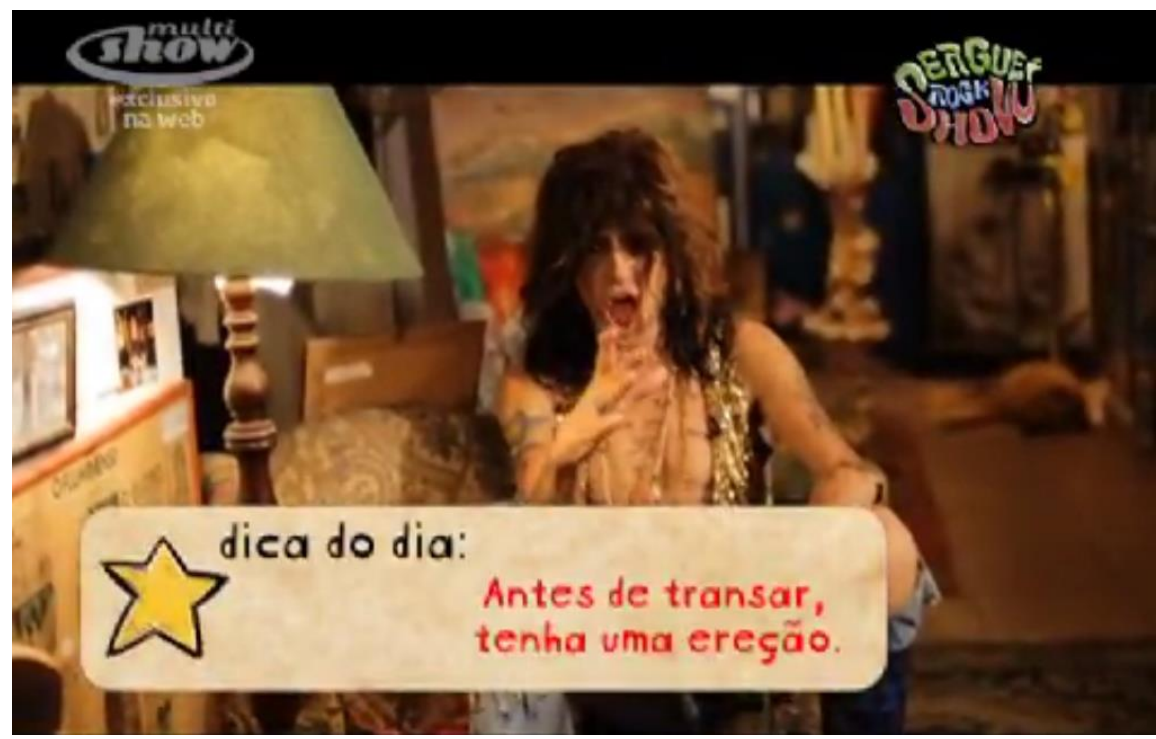

Fonte: Serguei Rock Show (2011).

No episódio 02 (Figura 03), Serguei é taxativo: "é proibido tocar funk na suruba!" Para ele: "Funk tem que ser proibido na suruba, porque senão você fica broxa. O pau não levanta você não sabe por que. Agora, se toca rock n'roll vem o tesão da guitarra, da coisa em si, aí já, todo mundo é capaz de gozar antes do tempo. Então rock n'roll é o ritmo e o som da suruba. Além de ser estilo de vida.".

Nessa dica o cantor (re)coloca o rock and roll na sua origem estéticacomportamental - a tríade: sexo, drogas e rock and roll. Para quem viveu os primeiros anos (e intensamente, até hoje) desse estilo de vida, pensar o ato sexual com outro ritmo, como no caso, o funk soaria como insulto. No seu conselho o roqueiro então mostra que na festa (suruba) tem que ter o elemento que dá "sabor" (energia), ou seja, o rock and roll. O próprio estilo musical, com seus instrumentos, por vezes são metáfora da sexualidade humana. A guitarra, por exemplo é um objeto fálico e os solos que os músicos fazem com ela, podem soar como um momento onanístico em determinado sentido. Portanto, nessa dica, a proposta da substituição do funk pelo rock demonstra a coerência com o próprio nome do programa, colocando o rock em perspectiva e fazendo dele um sujeito mediador de comportamentos, no caso, do underground old school para o novo pós-moderno. 


\section{midiática@ \\ REVISTA DO PROGRAMA DE \\ PÓS-GRADUAÇÃO EM COMUNICAÇÃO D \\ UNIVERSIDADE FEDERAL DA PARAIBA}

Além disso, a cena coloca o plano fechado na figura de Serguei, olhando diretamente para a câmera, com aspecto profético, sentado numa poltrona com um castiçal ao fundo, evocando sua figura contestatória (estética e conceitual) do padrão social vigente.

Figura 03. Episódio 02 "Funk tem que ser proibido na suruba".

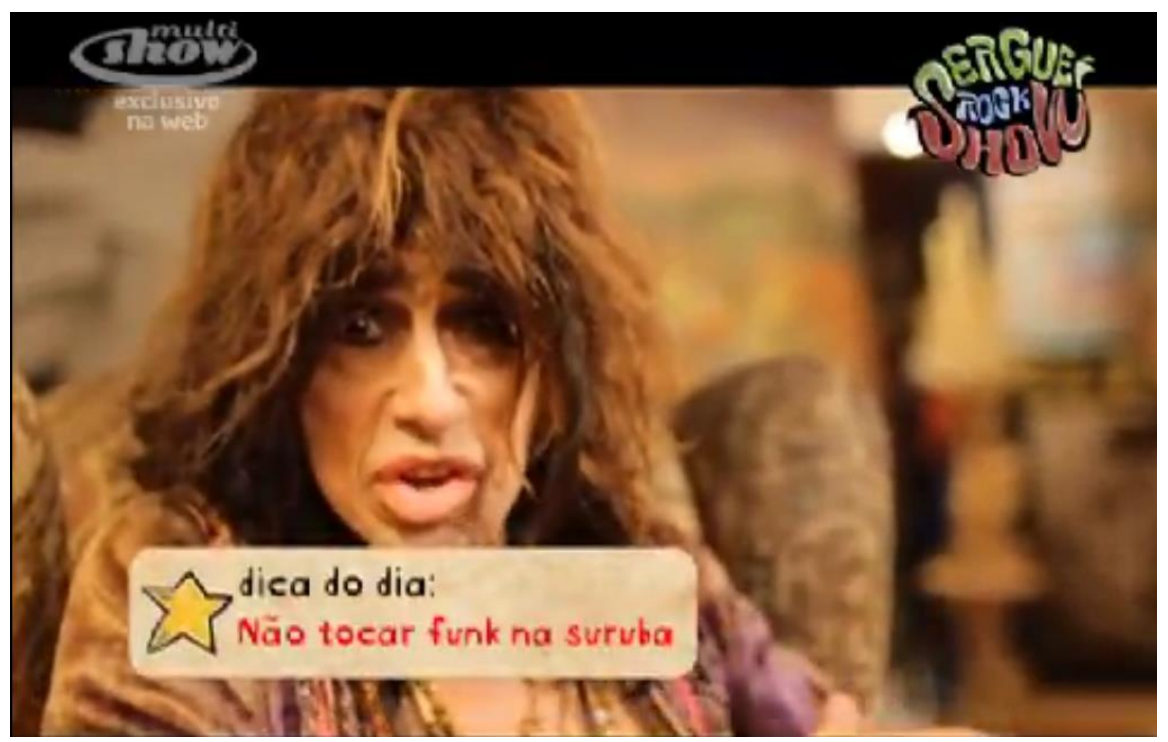

Fonte: Serguei Rock Show (2011).

No episódio 03 (Figura 04) Serguei dá a dica essencial do dia: “[...] Nunca se tranquem demais no armário! Abram a porta do armário e avancem em quem, sei lá, vocês quiserem". O termo "sair do armário" denota a condição de alguém que se assumiu homossexual, ou, mais além, que revelou a sociedade sua condição sexual (e de gênero). Na dica do episódio 03 no entanto, Serguei maximiza a intenção de esconder a sexualidade na frase "nunca se tranquem demais". Quer dizer, para ele as pessoas estão todas enrustidas existindo portanto, uma gradação entre ficar no armário por muito ou pouco tempo (ou além do tempo). Ele diz na sequência, como que num arroubo de liberdade: “avancem em quem vocês quiserem", ou seja, quando não der mais para segurar, explodam e exerçam a liberdade de expressão - e a vivam ao máximo.

Nesse trecho, as pequenas crises (GUMBRECHT, 2006) aparecem na modulação dos termos utilizados pelo cantor, pois na trivialidade do cotidiano, quando se aborda o tema "sair do armário" isso é feito (e recomendado) aos poucos, com passos 


\section{midiática@ \\ REVISTA DO PROGRAMADE \\ PÓS-GRADUAÇÃO EM COMUNICAÇÃO DA \\ UNIVERSIDADE FEDERAL DA PARAIBA}

curtos, com cuidado, sem querer expressar o choque, sem a intenção de magoar alguém com tal revelação. No entanto, Serguei já aconselha o escancaramento da situação e isso representa a extraordinariedade do quadro do programa. É a "comida chique" de Gumbrecht (2006), e é também a "fratura". (GREIMAS, 2002).

Figura 04. Episódio 03 "nunca se tranquem no armário".

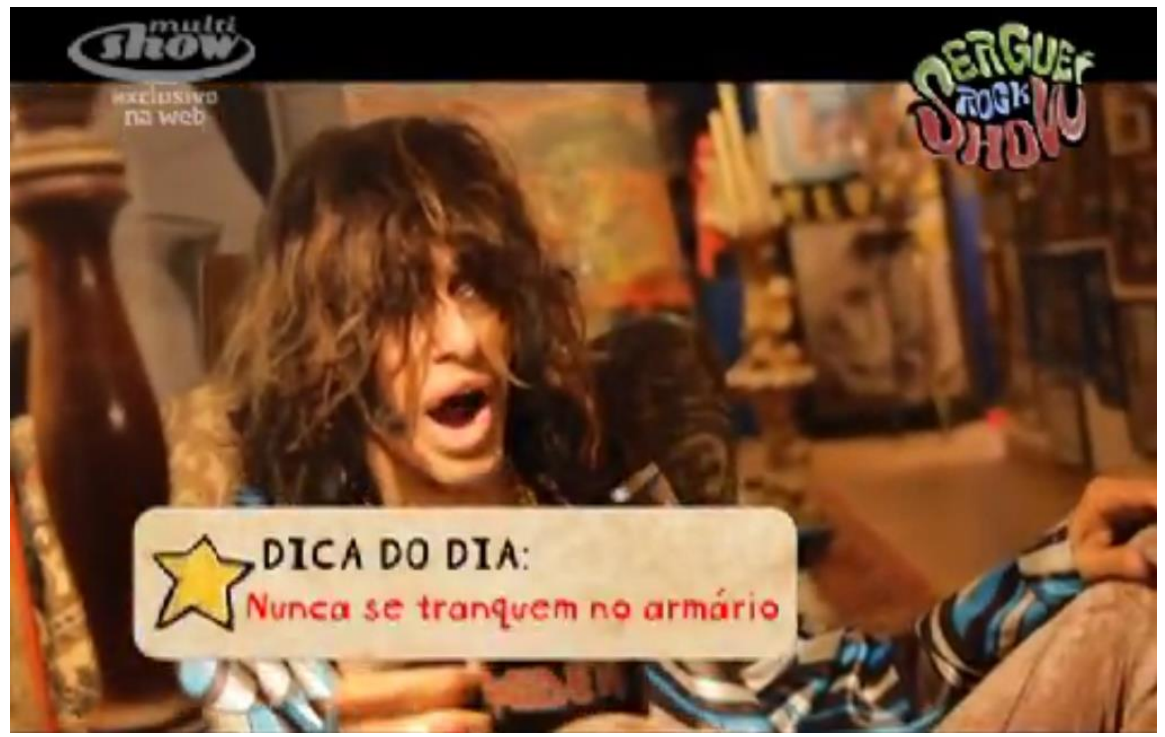

Fonte: Serguei Rock Show (2011).

No quarto episódio (Figura 05), Serguei dá sua dica expondo toda a visceralidade hippie que sempre carregou: "Se você viu o namorado da sua irmã, aí de repente, você achar que ele é interessante, nunca transe sem tesão, sem vontade, porque isso aí, é o fim da picada. Se você tiver vontade, ataca, segura, puxa pra você e divirtase, meu bem".

Nesse conselho, Serguei repete o tom de rebeldia do programa anterior no mesmo imperativo: "Nunca transe sem tesão". Essa dica revela-se necessária nos dias de hoje, onde a sexualidade - objeto de consumo - tomou contornos mercantis, com o advento de sites de encontros (e pornôs) e a disseminação dos nudes nas redes sociais. Sintoma da época é o desinteresse de uma editora brasileira em continuar a publicação da revista Playboy, ícone do sexy appeal no mundo todo. Ou seja, o nu, como expressão da sexualidade e impulsionador do desejo, deixou de ser o elemento surpresa e sim, do

\footnotetext{
${ }^{8}$ O conceito de fratura foi cunhado por Greimas (2002). Esse conceito faz um paralelo com Gumbrecht (2006) nas pequenas crises, denotando momentos de interrupção das isotopias cotidianas, desvelando assim, experiências estéticas.
}

Ano X, n. 19 - jul-dez/2017 - ISSN 1983-5930 - http://periodicos.ufpb.br/ojs2/index.php/cm 


\section{midiätica@e}

convencional. O recado de Serguei ultrapassa o âmbito da dimensão sexual: para transar (para fazer algo, construir, ser alguém, etc) é preciso ter tesão (garra, vontade, força, luta).

Figura 05. Episódio 04 "nunca transe sem tesão".

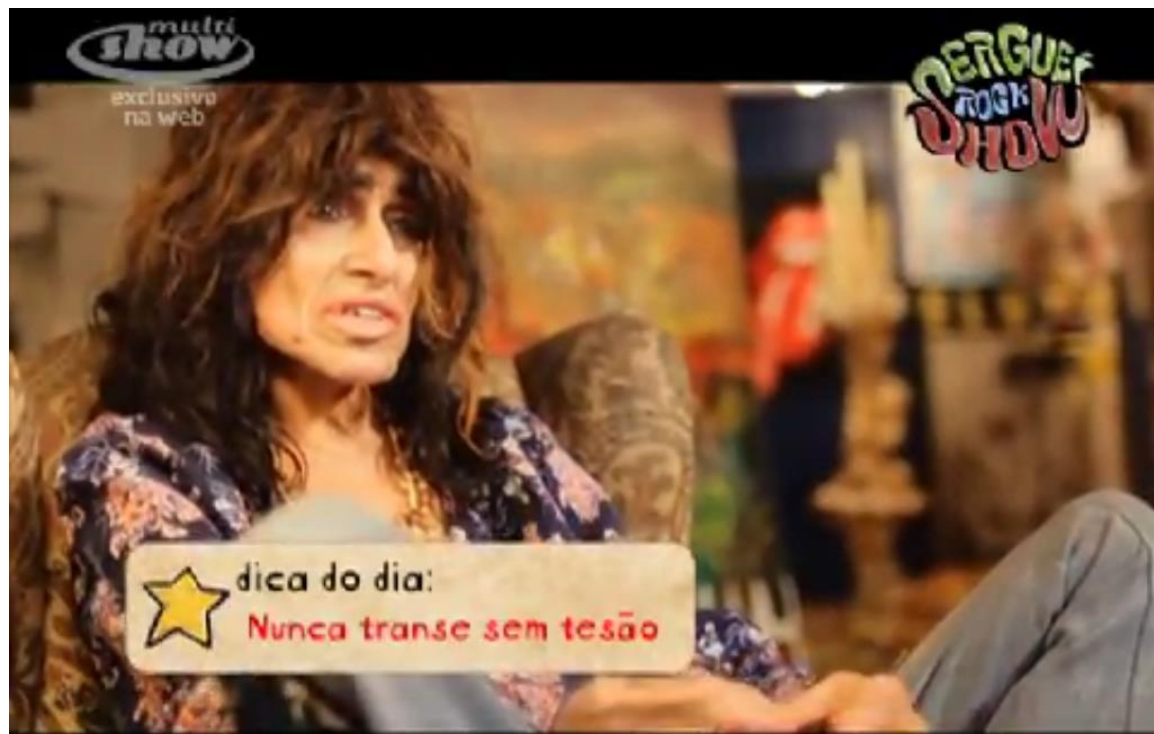

Fonte: Serguei Rock Show (2011).

Por fim, no episódio 05, Serguei fecha a sequência das cenas, aqui, analisadas com: "transem todos os dias". E em sua preleção, ele invoca a saúde à sua maneira (irreverente, sui generis): "Se você quiser ter uma vida saudável, transe todos os dias. Se você não tiver com quem transar, depende da pessoa, eu não sei [...] usar as mãos [...] eu acho que isso aí é que também evita muito câncer de próstata". 


\section{midiática@ \\ REVISTA DO PROGRAMA DE \\ PÓS-GRADUAÇÃO EM COMUNICAÇÃO DA \\ UNIVERSIDADE FEDERAL DA PARAIBA}

Figura 06. Episódio 05: "transe todos os dias".

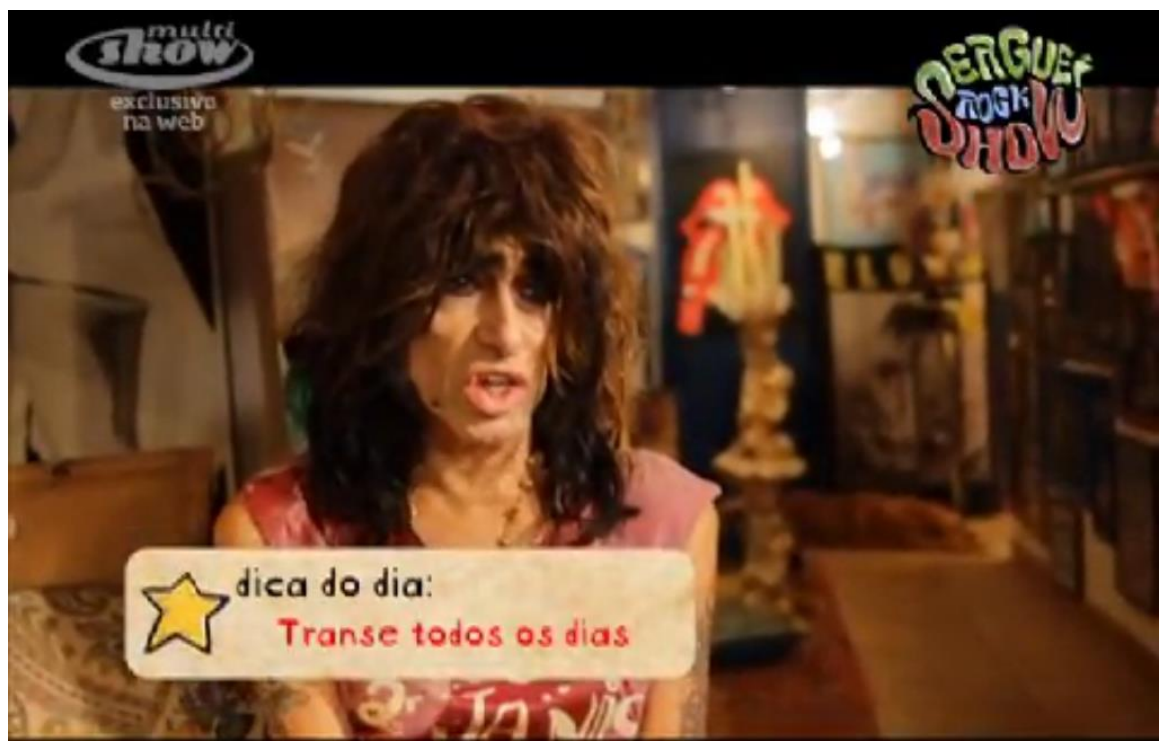

Fonte: Serguei Rock Show (2011).

Nesse episódio, Serguei mostra que a saúde passa pela sexualidade e que o ato sexual deve ser praticado, até para evitar doenças, no caso o câncer de próstata. A identificação com o conceito de Gumbrecht (2006) aqui acontece pelo estranhamento, conceito este formulado por Greimas (2002), ou seja, aquilo que rompe com o padrão esperado. Dizer para "transar todos os dias" como dica de sexo, sem algo específico, deixando um vazio e, de certa forma, frustrando expecativas, é ir contra comentários clichês sobre o tema. Serguei então, mostra sua irreverência nessa "orientação sexual" deixando claro que o óbvio ordinário tem efeitos ainda mais amplos que aparenta.

Em todas as sequências, aqui, apresentadas temos o enquadramento de uma figura que rompe com as expectativas em relação àquele que se coloca como sujeito "aconselhador", no caso, sempre um especialista no assunto. Serguei não é um sexólogo, mas um rockstar, uma figura conhecida e reconhecida por anos de histórias transgressoras. Sua aparência pode sugerir certa decadência, dentro dos padrões estéticos da sociedade - aparência inesperada esta que é colocada em primeiro plano: um roqueiro, que não mais pode separar sua história de sua imagem (o seu plano do conteúdo e da expressão), está sentado em uma poltrona, como um especialista pronto para dar conselhos, "Dicas de Sexo". Não é a sua formação que irá lhe garantir este 


\section{midiätica@e}

empoderamento, mas, sim, o enquadramento da câmera, considerando que no momento em que é filmado detém a autoridade, fala e será ouvido, proporcionará efeitos de sentidos, mesmo que para constituir o inesperado, romper padrões automatizados nas representações televisivas e, assim, estabelecer as fraturas - pequenas crises nas experiências estéticas que se fazem presentes no sensível do (tele)espectador. Em suma, a figura de Serguei, enquadrada na tela da TV, como dotado de autoridade no assunto, desencadeará a ruptura do olhar automatizado na ordem do anestésico ${ }^{9}$, para criar um novo olhar estésico, por meio de uma paródia que ressignifica o olhar por intermédio das "pequenas crises".

\section{Considerações finais}

Este trabalho teve como objetivo estudar o programa de televisão Serguei Rock Show, exibido em um canal de assinatura, com o artista e músico Sérgio Augusto Bustamante, popularmente conhecido no Brasil como Serguei. Por meio dele, foi possível realizar uma análise de alguns frames determinados do programa de TV, no quadro "Dicas de Sexo". A análise delimitou cinco cenas, de cinco episódios diferentes, que procurou evidenciar a relação do plano do conteúdo e do plano da expressão como potência de esperiências estéticas. Dentro deste contexto as pequenas crises de Gumbrecht (2006) puderam ser compreendidas no contexto do programa de tevê.

A quebra do fluxo contínuo do cotidiano que Gumbrecht (2006) aponta, fica claro em diversas cenas do programa analisado, e muitas outras passagens poderiam ser, aqui, expostas o que não é possível devido as limitações de espaço. Outros momentos poderiam exemplificar tanto ou mais o que os autores identificaram como pequenas crises, mas os fragmentos escolhidos também o mostram como tal, dando conta assim da problemática inicial. É uma forma de perceber os processos comunicacionais produzidos por ele, por sua irreverência, originalidade, estilo de vida e história.

Serguei pode ser e expressar diversos apontamentos que parecem óbvios na essência, mas que, juntamente, com as relações semi-simbólicas, mostram um valor estético complexo. Por isso, em cada quadro investigado, o artista mostra as rupturas da

\footnotetext{
9 Quando o formato do programa televisivo reproduz um padrão, já esperado pelo (tele)espectador, considera-se que "todo impulso em direção à estesia está ameaçado de uma recaída na anestesia" (GREIMAS, 2002, p. 80).
} 


\section{midiäticale}

logicidade e ordinaridade da sequência com sua narrativa aparentemente nonsense, o que na essência, já provoca os possíveis estranhamentos, risos, impactos do momento, ou seja, as pequenas crises, por meio do que Algirdas Julien Greimas (2004) propõe como uma leitura iconizante, compreendida como um objeto planar - nas imagens bidimensionais da tevê - que reconfiguram o modelo de quadros de aconselhamentos, por meio do crivo de leitura, podendo até mesmo ser visto como uma paródia do estilo exaustivamente apresentado nas narrativas audiovisuais do gênero.

\section{Referências}

DIDI-HUBERMAN, Georges. O que vemos, o que nos olha. São Paulo: Editora 34, 1998.

FLOCH, Jean-Marie. Alguns conceitos fundamentais em Semiótica Geral. Documentos de Estudo do Centro de Pesquisas Sociossemióticas. São Paulo: Centro de Pesquisas Sociossemiótica, 2001.

GREIMAS, Algirdas Julien. Da Imperfeição. São Paulo: Hacker Editores, 2002.

GREIMAS, Algirdas Julien. Semiótica figurativa e semiótica plástica. In: Oliveira, Ana Cláudia (org.). Semiótica Plástica. São Paulo: Hacker Editores, 2004.

GUMBRECHT, Hans. Pequenas crises: experiência estética nos mundos cotidianos. In: GUIMARAES, C; LEAL, B; MENDONÇA, C. (Org.). Comunicação e experiência estética. Belo Horizonte: Editora UFMG. Belo Horizonte, 2006: 50-63.

HEIDEGGER, Martin. Der Ursprung des Kunstwerks (1936). Ders.: Holzwege. Frankfurt aM, 1950.

KANT, Immauel. Immanuel Kants Kritik der reinen Vernunft. Mayer \& Müller, 1889.

PENAFRIA, Manuela. Análise de filmes - conceitos e metodologia(s). In: CONGRESSO SOPCOM, 6, 2009. Disponível em: <http://www.bocc.ubi.pt/pag/boccpenafria-analise.pdf >. Acesso em: 18 nov. 2015

PINHEIRO, Igor Fernandes. Não fale com as paredes: contracultura e psicodelia no Brasil. 2015. 238f. Dissertação (Mestrado em História) - Universidade Federal Fluminense, Instituto de Ciências Humanas e Filosofia, Departamento de História, 2015 .

SEEL, Martin. Eine Asthetik derNatur. Frankfurt am Main: Suhrkamp, 1991.

SERGUEI NEWS. BLOG. Disponível em:

http://sergueinews.blogspot.com.br/2015/09/serguei-jovem-guarda.html. Acesso em:

25/maio/ 2016.

SCHILLER, João. Henrique. Serguei: o anjo maldito. São Paulo: CZA Editora, 1997.

Ano X, n. 19 - jul-dez/2017 - ISSN $1983-5930$ - http://periodicos.ufpb.br/ojs2/index.php/cm 